\title{
Corinne Bayle, Paul Éluard. Le cœur absolu. Étude de "Capitale de la douleur" (1926)
}

\section{Tania Collani}

\section{(2) OpenEdition}

1 Journals

\section{Edizione digitale}

URL: http://journals.openedition.org/studifrancesi/1611

DOI: 10.4000/studifrancesi. 1611

ISSN: 2421-5856

\section{Editore}

Rosenberg \& Sellier

\section{Edizione cartacea}

Data di pubblicazione: 1 novembre 2014

Paginazione: 632-633

ISSN: 0039-2944

\section{Notizia bibliografica digitale}

Tania Collani, "Corinne Bayle, Paul Éluard. Le cœur absolu. Étude de "Capitale de la douleur" (1926) »,

Studi Francesi [Online], 174 (LVIII | III) | 2014, online dal 01 novembre 2014, consultato il 18 septembre 2020. URL : http://journals.openedition.org/studifrancesi/1611; DOI : https://doi.org/10.4000/ studifrancesi. 1611

Questo documento è stato generato automaticamente il 18 settembre 2020.

\section{(c)}

Studi Francesi è distribuita con Licenza Creative Commons Attribuzione - Non commerciale - Non opere derivate 4.0 Internazionale. 


\title{
Corinne Bayle, Paul Éluard. Le cour absolu. Étude de "Capitale de la douleur" (1926)
}

\author{
Tania Collani
}

\section{NOTIZIA}

CORINNE BAYle, Paul Éluard. Le cœur absolu. Étude de "Capitale de la douleur" (1926), Presses Universitaires de Rouen et du Havre, 2013, pp. 226.

1 Professoressa di Letteratura francese dell'Otto-Novecento all'École Normale Supérieure di Lione, Corinne Bayle pubblica uno studio su Capitale de la douleur di Éluard, nell'anno in cui la raccolta figura nel programma della prova dell'agrégation - e Les Mains libres di Éluard sono in quello del baccalauréat. Specialista di Gérard de Nerval, Théophile Gautier, Pierre Reverdy e René Char, Corinne Bayle arricchisce la sua lettura del poeta francese con un corollario di riferimenti al romanticismo e al surrealismo, dando al lettore un'immagine di Éluard complessa e giusta - nella sua conclusione Corinne Bayle puntualizza il senso profondo del «cœur absolu» evocato nel titolo, ricorrendo all'idea di «justesse d'un chant travaillé».

2 Riprendendo l'impostazione metodologica della collana «Cours» che accoglie il suo volume, Corinne Bayle parte con un capitolo sulla genesi dell'opera, soffermandosi su numerosi elementi biografici; i tre capitoli successivi sono dedicati alla presentazione e all'analisi dell'opera stessa. Capitale de la douleur è la prima antologia poetica di Éluard e copre i suoi primi otto anni di creazione. Presenta già tutte le caratteristiche della poesia della maturità del poeta: la raccolta di componimenti eterometrici (poesia in versi e in prosa, metro e verso libero), l'influenza del récit de rêve (marchio di fabbrica del surrealismo), il legame tra testo e immagine (i collages di Max Ernst in Répétitions, prima sezione della raccolta, preludono a future collaborazioni poetico-artistiche: a $\mathrm{p}$. 45 un refuso attribuisce Les Mains libres, del 1937, a Éluard e Max Ernst; a p. 97 il volume 
è giustamente attribuito a Éluard e Man Ray). Il volume si chiude con un'appendice di estratti critici su Éluard (Pierre Emmanuel, Gaston Bachelard, Gaëtan Picon, Henri Meschonnic, Bernard Noël, Jean-Marie Gleize, Michel Murat).

Opera sicuramente singolare, Capitale de la douleur esprime tuttavia una poetica la cui modernità si compone di elementi affinati in un contesto collettivo. La sollecitazione continua dei confini della realtà (poetica del «rendre réel», come in Donner à voir del 1939) passa attraverso una sperimentazione in campo metrico e formale: sebbene si constati una generale tendenza all'abbandono della rima, ci sono poesie che ricorrono all'alessandrino o al decasillabo. Corinne Bayle individua un'influenza duplice nella poesia di Éluard: da una parte la tradizione della poesia medievale (soprattutto quella della canzone), del "blasone" (poesia descrittiva d'elogio che ha avuto una grande diffusione nel Cinquecento con Clément Marot) e di Baudelaire; dall'altra le forme dell'inizio del Novecento, l'haïku, il calligramma e tutta l'avanguardia che Éluard frequentava.

4 A livello tematico, Capitale de la douleur si impone per l'immancabile presenza dell'amore e della figura femminile, dello sguardo e degli "occhi fertili", porta privilegiata e specchio dell'immaginario. Il risultato è una poesia fatta di immagini, dove le frontiere tra il visibile e il leggibile sono molto labili: è una poesia ispirata al mondo, ma che "riqualifica il mondo" (parafrasando il titolo dell'ultimo capitolo di Corinne Bayle), attraverso un atto creatore a tutto tondo: recupero del passato proiettato verso il presente, innovazione e riferimenti contemporanei, analogie e sinestesie moderne, interiorizzazione del mondo sensibile ed esteriorizzazione del sogno. 